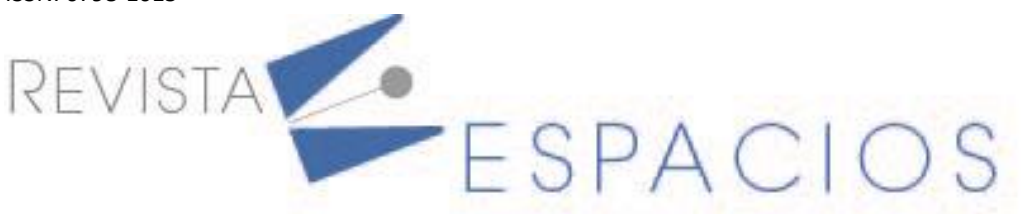

Vol. 41 (43) $2020 \cdot$ Art. 18

Recibido/Received: 05/08/2020 • Aprobado/Approved: 19/09/2020 • Publicado/Published: 12/11/2020

\title{
Water management strategies in hotels in arid regions: results and implications from a case study on Gran Canaria island (Spain)
}

\section{Estrategias en la gestión de los recursos hídricos en hoteles de regiones áridas: resultados e implicaciones de un estudio de caso en la isla de Gran Canaria (España)}

POPELY, Deborah ${ }^{1}$

MORENO-MELGAREJO, Alberto²

\begin{abstract}
Hotels are water-intensive businesses, and water scarcity presents a pressing problem for managers who rely on an uninterrupted supply of water to meet guests' needs and maintain profitability. The purpose of this qualitative-case study was to explore strategies that hotel managers used to successfully maintain adequate water supplies in arid regions. Data were collected from semistructured interviews and hotel water usage reports from three hotels in Spanish island of Gran Canaria. This study may contribute to business practice by illuminating processes that hotel managers, employees, guests, and partners, can take to improve environmental performance and align practices with water governance. key words: water management strategies, hotel water supply management, arid regions, Gran Canaria.
\end{abstract}

\begin{abstract}
Resumen
El propósito de este estudio de caso cualitativo ha sido explorar estrategias que los hoteles utilizan para mantener el suministro adecuado de agua en regiones áridas. Los datos fueron recogidos a partir de entrevistas semiestructuradas y el análisis de informes de uso de agua de tres hoteles en la isla de Gran Canaria. Este estudio contribuye a la práctica hotelera al identificar los procesos que los gerentes, empleados, huéspedes y otros agentes pueden llevar a cabo para mejorar el desempeño.

Palabras clave: estrategias de gestión hídrica, gestión del suministro de agua, regions áridas, Gran Canaria.
\end{abstract}

\section{Introduction}

Environmental degradation and depletion of resources are gaining attention as important business management issues. The scarcity of natural resources can disrupt supply chains and produce unnecessary risks for businesses. Water scarcity is emerging as a critical problem for water-dependent businesses such as agriculture, meat, beverages, and tourism. Tourism and hospitality businesses, particularly hotels, rely on a sustainable supply of high-quality water. This case study exposed strategies that hotel managers used to maintain adequate water supplies in limited water conditions. By revealing exemplary water supply strategies used by hotel managers in

\footnotetext{
${ }^{1}$ Associate Professor. Kendall College. National Louis University (U.S.).dpopely@nl.edu

${ }^{2}$ Head of Education and Humanities Department. Universidad Europea de Madrid. alberto.moreno@universidadeuropea.es
} 
arid regions, the findings of this study could help other managers become better prepared to address threats to their water supply.

Hotel managers need adequate water supplies to maintain profitability and customer satisfaction (Gössling et al., (2012; Kasim et al., (2014). The water needs of hotel guests can be two to three times more intensive than those of residents (Barberán et al., (2013; Kasim et al., 2014; Styles et al., (2015). The general business problem is that water scarcity negatively affects hotels, resulting in operational and marketing challenges, especially in arid regions. The specific business problem is that some hotel managers lack strategies for maintaining adequate water supplies in arid regions.

The current research sought to contribute to effective business practice by identifying strategies that hotel managers operating in an arid region used to address issues related to water, an increasingly scarce but essential natural resource. Economists predict that water scarcity will be among the leading business risks in the coming decade (World Economic Forum, 2016). The tourism industry heavily depends on water supply, especially in the hotel sector, which consumes water to accommodate, feed, and entertain guests (Barberán et al., 2013). Hotels are more than likely to face water shortages because they tend to be located in warm climates, in coastal areas and on islands where there are inherent water challenges (Styles et al., 2015). Water scarcity increases costs and complicates marketing for hotel managers in these regions. To maintain adequate water supplies, hotel managers typically employ water conservation, water reuse, and resource recovery strategies, producing potential cost savings and marketing benefits (Becken \& Dolcinar, 2016; Bruns-Smith et al., f2015). Therefore, identifying effective water supply strategies used in a historically water-challenged tourism environment could help other hotel managers reduce costs, increase profitability, and ensure the ongoing availability of water resources when supplies are uncertain or limited.

\section{The Resource-Based View (RBV) and hotel water supply}

The RBV emerged in the 1980s and described how the exploitation of resources could produce a competitive advantage for businesses. Wernerfelt coined the term in 1984, laying the foundation for a theoretical framework that has dominated the literature for more than 30 years (Božič \& Cvelbar, 2016). The RBV framework involved looking at the firm as a broad set of resources rather than a collection of products (Salazar, 2017). Scholars credited Barney (1991) with establishing the link between the RBV and competitive advantage, differentiating among various types of resources and identifying the interactions between them as drivers of firm performance (Salazar, 2017). The RBV is consistent with several other theories for explaining why some firms outperformed others, including structure-conduct-performance (SCP), neoclassical economics, and evolutionary economics (Barney, 1991). The assumptions that shaped these other resource-based approaches were similar to those of the RBV; for instance, all the approaches described long-lasting differences in the ways resources and capabilities might be distributed across firms (Barney, 2001).

Resources that enable a firm to efficiently or effectively produce and market products that create value by satisfying one or more market segments may come in the form of assets, capabilities, processes, attributes, information, and knowledge (Barney, 2001). The RBV encompassed both tangible and intangible resources. Tangible resources included financial or physical assets, while intangible resources included factors situated in the firm's human, intellectual, and relational capital (Božič \& Cvelbar, 2016). Valuable, rare, imperfectly mobile, and nonsubstitutable (VRIN) resources confer the greatest strategic advantage (Enriquez de la O, 2015). One critical premise was that only VRIN resources could produce a long-lasting competitive advantage and lead to above-average returns (Barney, 2001). Value, according to Barney (2001), is a function of information asymmetries as to the future value of resources in strategic factor markets. In other words, valuable resources are those that can be attained at below market rates (prices) and generate above market-rate returns (Salazar, 2017). 
Throughout previous literature, researchers found that effective management of natural resources offered hotels competitive advantages in the areas of operational efficiency, cost-savings, and market positioning. Research on tourists' decision-making showed an increasing marketing benefit for hotels that practiced resource efficiency and environmental responsibility (Bruns-Smith et al., 2015). A related mixed-methods study of Spanish hotel managers found that quality management and environmental management provided cost savings and market differentiation that could result in a competitive advantage (Molina-Azorín et al., f2015). Findings from a study on travel and tourism businesses from 2003 to 2014 indicated that environmental performance positively impacted financial performance in the hotel industry on both aggregate and individual dimensions, mainly through resource use reduction and product innovation (Tan et al., f2017).

\subsection{Tourism, hotels, and water resources}

The tourism sector consumes large amounts of water, and conservation is an important management issue for the industry (Gössling, 2015). Tourism accounted for less than 1\% of worldwide water use (DeSouza, 2016); however, consumption varies regionally and can be higher where tourism is a larger factor in the economy (Gössling et al., 2012). Tensions between tourists and residents over water use are particularly evident in countries where tourism is a key industry and revenue generator (Guarino, 2017). Water challenges have increased at tourism destinations in the United States, Australia, Central America, Europe, the Middle East, and China (Gössling et al. 2012).

Water use in tourism will increase by 2020 due to tourism growth, hotel development, and water-related recreation (Becken, 2014). The resulting economic and social tensions could jeopardize the organizations' licenses to operate and damage the reputation of hotel brands in many locations (Styles et al., 2015). Responsible conduct related to water use and conservation by all stakeholders is essential for sustainable development (Marques et al., ( 2016).

Hotel operators employ water resources to meet a wide variety of customer needs, including sanitation, nutrition, and recreation (Gössling et al., 2012; Kasim et al., 2014). For hotels, water is "an essential factor of production" (Barberán et al., 2013, p. 181). Most hotel managers engage in some degree of water stewardship, employing a variety of water conservation, water reuse, and water recovery strategies. Water efficiency strategies produce substantial cost savings for hotels (Becken \& Dolcinar, 2016; Bruns-Smith et al., 2015).

It is well documented that hotel guests use substantially more water than their local counterparts (Kasim et al., 2014; Styles et al., 2015). Climate, service level, number of rooms, occupancy, and range of amenities determined total hotel water use (Barberán et al., 2013). Public spaces such as reception areas, restaurants, kitchens, lounges, pools, and gyms accounted for approximately half of hotel water use. Hot water alone accounts for nearly a third of guestroom water use (Barberán et al., 2013). Hotel water use also required increased energy consumption, particularly where desalinated water was prominent (Becken, 2014).

\section{Purpose and methodology}

The purpose of this case study was to explore strategies hotel managers used to maintain adequate water supplies in arid regions. Findings from this study may help hotel managers contribute to business practice by improving hotel water stewardship and aligning hotel water supply strategies with sustainable water governance. It may also influence employees, guests, and other partners to engage in water conservation. Identifying new strategies for water supply management could have implications for a more equitable distribution of water among stakeholders.

Methodology and Design. The selected research methodology was a qualitative method with a multiple case study design. Qualitative methods are particularly useful for exploring how resources, capabilities, or competencies emerge and develop within firms (Dasgupta, 2015). Therefore, the qualitative methodology aligned well with the RBV, this study's conceptual framework. The case study design is well suited to generating 
relevant knowledge about management issues (De Massis \& Kotlar, 2014) and it is ideal for observing rich information about the underlying and idiosyncratic effects of resource-based strategies on firm performance (Dasgupta, 2015).

Sampling and Participants. Purposive sampling was used to select the cases and participants. Purposive sampling entails the assumption that the research subjects have unique or important perspectives on the research question (Robinson, 2013). The main criterion for selection of cases is that they are suitable for the questions under investigation (Diefenbach, 2009). A multiple case study design consisting of three organizations is sufficient for exploring a research question and identifying rival explanations (Yin, 2017). Three hotels were chosen based on their recognition for environmental management and their diversity of sizes and service levels (3-, 4-, and 5star). The eligibility requirement for study participants was that they were hotel managers who had used strategies to successfully maintain adequate water supplies in these hotels. Using semistructured interviews allowed gaining an understanding of the phenomenon through participants' eyes. In qualitative research, data quality increases when researchers interview several well-informed participants who can provide different perspectives on the research question (De Massis \& Kotlar, 2014).

In addition to interviews, document review was employed for this study. Document review has the benefit of enhancing study validity (Baskarada, 2014). Documents related to water policies and usage at each hotel were collected, reviewed, and analyzed. To achieve triangulation, data from two sources was collected and analyzed, interviews and documents, to verify the consistency and completeness of data. This procedure ensured that findings were valid. De Massis and Kotlar (2014) described cross-case comparison as another way for researchers to enhance the credibility of findings.

Data Saturation. In case study research, data saturation occurs when no further new data emerges with subsequent interviews (Fusch \& Ness, 2015; Robinson, 2013) and there is no correlation between the number of interviews and the validity of conclusions (Diefenbach, 2009). Saturation depends on the depth and richness rather than the amount of data (Malterud et al., $(2016)$. The topic and the extent of data help determine the number of interviews (Yin, 2017). We interviewed a total of nine managers at three different hotel sites and the corporate office, conducted member checking to deepen our understanding, and explored water supply reports from each hotel until data saturation was achieved.

Data Analysis. The analysis in this study began with examining the various sources of data, including interview recordings, member checking interviews, and water use documents. All collected data was coded with the aid of the qualitative software program Atlasti. Yin (2017) pointed out that it is necessary to convert all evidence, including notes and other archival documents, into a form that can be coded in the software. For this reason, interviews and documentary evidence were also coded in Atlasti to support methodological triangulation. More than 300 data points were coded into Atlasti, which formed 50 topics that were ultimately grouped into four themes discussed in the findings.

Limitations: Limitations are possible weaknesses in a study outside the researcher's control (Hancock \& Algozzine, 2017). A limitation of case study research is that one cannot generalize to a broader population (Stake, 1995). Another limitation was the sampling method used to recruit participants. All participants were managers at different units of the same hotel group and therefore more inclined to provide reinforcing rather than contradictory information. Also, an inherent self-selection bias existed because these managers were volunteers who were eager to talk about their accomplishments. Diefenbach (2009) observed that in organizations subordinates might have difficulty in diverging from the views of upper management. Departmental managers could have felt compelled to align their statements with those of superiors at each hotel, despite assurances of confidentiality. Fortunately, documentation provided important methodological triangulation to offset potential positive bias in the findings. 


\section{Findings}

The main research question for this study is, what strategies do hotel managers use to maintain adequate water supplies in arid regions? In order to answer the research question four overarching themes have been defined:

- value water as a strategic business resource,

- mitigate risks of natural resource scarcity,

- promote water efficiency and conservation practices, and

- sustain supply through Corporate Water Stewardship (CWS).

Several subtopics reoccurred throughout these themes, including water cost, water quality, desalination, reuse and recycling, a culture of water conservation, and collaboration in water governance. These four themes are structuring research outcomes including related content and discussion as included in the following table:

Table 1

Structuring research outcomes:

selected themes and related content

\begin{tabular}{|c|c|}
\hline \multirow{4}{*}{$\begin{array}{c}\text { Theme } 1 . \text { Value water as a strategic } \\
\text { business resource }\end{array}$} & Hotel water use \\
\hline & High cost of water \\
\hline & Hotel performance and competitive advantage \\
\hline & Water quality \\
\hline \multirow{3}{*}{$\begin{array}{l}\text { Theme } 2 \text {. Mitigate risks of natural } \\
\text { resource scarcity }\end{array}$} & Water scarcity \\
\hline & Hotel water supply \\
\hline & Business risk \\
\hline \multirow{10}{*}{$\begin{array}{c}\text { Theme } 3 \text {. Promote water efficiency } \\
\text { and conservation practices }\end{array}$} & Water efficiency and conservation \\
\hline & Water management plans \\
\hline & Efficient fittings \\
\hline & - Housekeeping. \\
\hline & - $\quad$ Laundry \\
\hline & - $\quad$ Kitchens \\
\hline & - $\quad$ Pools \\
\hline & - $\quad$ Cooling and irrigation \\
\hline & - $\quad$ Awareness (staff and guests) \\
\hline & Environmental certifications \\
\hline \multirow{2}{*}{$\begin{array}{l}\text { Theme 4. Sustain supply through } \\
\text { Corporate Water Stewardship (CWS) }\end{array}$} & Hotel water stewardship \\
\hline & Climate change \\
\hline
\end{tabular}

Source: Own elaboration

\subsection{Theme 1. Value water as a strategic business resource}

Analysis of participant interviews and documents demonstrated that hotel managers in this study linked access to water resources with performance and competitive advantage.

Hotel water use. The intensive use of water in hotels has been documented in multiple studies (Barberán et al., 2013; Gössling et al., 2012; Kasim et al., 2014; Styles et al., 2015). Participants discussed a similarly high level of water demand at their properties. Analysis of water use records and reports from the hotels in this study further underscored the value of water. Larger and more luxurious properties have been found to use more water (Barberán et al., 2013; Styles et al., 2015). The larger and more upscale hotels included in this study also used more water. Water efficiency, the extent to which managers optimized water use for their properties, appeared 
to align with the total number of rooms, rather than the overall size of the property or the level of service. The most water efficient operation was the 4-star property with 1,136 rooms, rather than the 5-star property with 561 rooms. Large size and high occupancy rates can spread fixed costs over a larger customer volume, producing greater water efficiency (Zhang et al., (2014). Age, design, amenities, and climate could also account for different levels of water efficiency in different properties (Da Rosa \& Silva, 2017; Styles et al., 2015; Zhang et al., 2014). However, researchers have shown that the knowledge and dynamic capabilities of managers also could account for differences in environmental performance (Del Mar Alonso-Almeida et al., 2017).

High cost of water. Managers in this study frequently expressed dissatisfaction with the high cost of water. Document and interview data showed that water was an unusually large percentage of the hotels' operating budgets (10\%) at these properties, significantly above average of $6 \%$ for all utilities (AHLA, n.d.), and was a major motivator for managers' water efficiency efforts. Razumova et al., (2016) and Deya-Tortella et al., - (2017) proposed a weak correlation between water supply strategies and water costs, but Bell et al., (2013) and others argued that scarcity would lead managers to conserve water as a hedge against price increases and regulations. Managers included in this study appeared to respond to water costs as predicted by Bell et al. (2013). With operating costs and occupancy expected to rise in 2018 (CBRE Hotels, 2018), the managers included in this study appeared to be highly motivated to reduce water costs to meet financial objectives and achieve profitability.

Barberán et al. (2013) observed that water costs might be particularly high in arid and semiarid regions and small islands that depend on desalination or water importation. Participants consistently blamed the high price of water on the cost of desalination.

Hotel performance and competitive advantage. Participants in this study confirmed the applicability of the RBV to hotel environmental performance. RBV theorists argued that firms could achieve a long-lasting competitive advantage by optimizing internal resources and capabilities (Božič \& Cvelbar, 2016; Enriquez de la O, 2015; Tan et al., 2017). Water is "an essential factor of production" for hotels (Barberán et al., 2013, p. 181). Participant 5 agreed that water offered a strategic advantage and described water as "an essential and strategic good both for the basic needs of customers [showers and toilets], for direct services [swimming pools and showers and water used in spa facilities] and indirect uses [water used in kitchens for food preparation]." Barney (2001) contended that water is a VRIN resource and therefore might confer the greatest strategic advantage, a sentiment reflected in Participant 5's comment that hotel managers should "treat water as if it were gold."

Water quality. Custodio et al., (2015) commented that while some anxiety about water scarcity in the Canary Islands is appropriate, quality may be a bigger source of concern than quantity. Although local tap water meets basic Spanish health standards, it has high mineral content (lime), and the government does not recommend drinking it. Indeed, participants complained about the poor quality of water from municipal sources nearly as much as they complained about the cost. Several participants stated that to them, water quality was a greater business risk than scarcity.

All three hotels included in this study used secondary treatment systems to remove minerals and improve the taste of water for use in food and beverages and to protect equipment from damage that could lead to high repair or replacement costs. Participant 3, a food and beverage manager of a 3-star property, explained that poor quality water could also impact the cleanliness of dishes, glassware, and cutlery, resulting in customer complaints. Additional water treatment steps further increase operating costs and generate waste. According to Participant 9, a manager at the corporate office, the two larger hotels in the study own their own reverse osmosis water treatment equipment, but the smaller one rents it due to the high capital investment costs. 


\subsection{Theme 2. Mitigate risks of natural resource scarcity}

The findings showed that resource scarcity produced substantial business risks for the hotel managers in this study. Participants stressed the need for a continuous, uninterrupted supply of water. Analysis of hotel documents did not directly address this theme, but data analysis demonstrated the extensive need for continuous water supply.

Water scarcity. Water is a scarce commodity in the Canary Islands, and the seasonal nature of tourism results in spikes in water use that strain available resources (Custodio et al (2016). The Canary Islands are volcanic islands in the Atlantic Ocean located at the same latitude as the Sahara Desert (Custodio et al., 2016). The climate is temperate and dry and marked by natural resource scarcity. The islands receive an average rainfall of $325 \mathrm{~mm}$ per year, just above the $300 \mathrm{~mm}$ threshold that defines arid zones in Spain (García-Rodríguez et al., - (2016). Participant 5 stressed that "the greater the water scarcity, the bigger the impact on the hotel's business."

Hotel water supply. The findings indicated that hotel operations depend heavily on continuous water supply and interruptions can have negative consequences on operations, customer satisfaction, and profitability. Participants identified gardens and pools as the most water-intensive features of their properties and therefore the most dependent on adequate water resources. Participants also mentioned elaborate gardens as a necessary aesthetic feature of the hotel environment, especially at larger resort properties. Swimming pools are another major feature of the resort environment that participants noted. Pools require large amounts of water for filling, filtration, maintenance, and treatment. Becken et al.,(2014) stated that pools might account for $3 \%$ to $20 \%$ of water use in hotels, and Gössling et al. (2012) asserted that the presence of a pool could increase water usage by $87 \%$.

Water shortages could force hotel managers to curtail or modify these important amenities. Participant 5 said dramatic interruptions in supply could force managers to shut down services such as spas and pools. Long-term interruptions could impact access to pool showers or restrooms in common areas. A major scarcity event could require temporarily closing off rooms and moving guests to other parts of the property. According to Participant 1 and others, any of these scenarios could diminish customer satisfaction and impact profitability.

Business risk. Bell et al. (2013) proposed a typology for explaining the RBV under conditions of natural resource scarcity. Consistent with the typology, water availability in the Canary Islands is characterized by limited renewability due to scant rainfall and ongoing scarcity due to increasing demand and dwindling groundwater supplies. The Islands also suffer from degeneration of overall and preferred quality of water supplies; in some locations reserves have reached the point of nonrenewability (Bell et al., (2012); Custodio et al., (2016). Moreover, the Canary Islands suffer from local degeneration of a typically renewable resource, which produces both overall scarcity and scarcity of preferred quality water supplies.

Bell et al. (2012) explained that a formerly renewable resource could become nonrenewable as the result of environmental damage. Custodio et al. (2016) proposed that intensive exploitation of groundwater in the Canary Islands has depleted water reserves in some areas to the point of nonrenewability. The hotel managers in this study relied heavily on avoidance and allocation strategies to mitigate scarcity. For instance, participants spoke extensively about preventing leaks, reducing flow rates from faucets and fixtures, and employing creative lowwater cleaning strategies. They also discussed sustainment strategies such as using cisterns to maintain a backup supply in case of interruptions. Participant 5 summed up these strategies as "rational use of water that, among others, does not generate any...waste, which would undermine the economic objective of the business unit itself." 


\subsection{Theme 3. Promote water efficiency and conservation practices}

The focus of Theme 3 is the use of water efficiency and conservation practices by hotel managers to ensure a sustainable, continuous supply of high-quality water. Previous research on hotel environmental performance indicated that the most widespread environmental hotel practices are low-cost measures that result in energy, water, and waste management savings (Becken, 2014; Becken \& Dolcinar, 2016; Becken et al., 2014; Bruns-Smith et al., 2015). According to hotel water use reports and interviews, managers at the three hotels in this study applied the same types of low-cost, practical, and cost-saving practices that appeared in other studies of water supply management.

Water efficiency and conservation. Comparing the practices of these hotel managers to best practices and benchmarks of excellence for water management in the European hospitality sector could help extend the understanding of hotel water efficiency and conservation practices. In interviews and documents, participants directly addressed seven categories of practices identified by Styles et al. (2015): water management plans, efficient fittings, housekeeping, laundry, kitchens, pools, and cooling and irrigation.

Water management plans. Monitoring and benchmarking of water consumption is fundamental to effective water supply strategy (Styles et al., 2015). Measurement is a necessary first step for identifying leaks and opportunities to reduce water use. This strategy aligns with the emerging practice of water footprinting among water-intensive businesses. The managers in this study emphasized water planning and budgeting for their hotels based on historical data. Participant 6, the general manager of a 5-star property, said: "Measure, measure, measure...to avoid any leakage. That's the best way to save." Participant 9, a manager at the corporate office, said that by detecting and quickly attending to leaks, the hotels collectively saved $12 \%$ of total water consumption. He added "[Leak prevention] is the number one priority. It is the cheapest way and delivers the greatest cost savings and highest ROI." Hotel documents indicated that managers either employ or contract with technical experts to periodically check all pipes and equipment for leaks and efficient functioning through segregated metering.

Efficient fittings. Reducing water use in guest areas by installing low flow fittings or retrofitting existing fixtures is a fundamental and cost-effective best practice for hotels (Styles et al., 2015). This strategy applies to guest rooms, pool change areas, and public areas. Many of these practices are estimated to achieve payback in one year or less, while basin and toilet retrofits can pay back in three to six years (Styles et al., 2015). In the three hotels included in this study, water flow rates were higher for hand basins and showers than targeted by Styles et al. (2015). Hotel documents indicated that retrofitting of hand basins was in progress, but consistent with other studies, this strategy was delayed due to the greater time, planning, and resources involved. Participant 6 , the general manager of a 5-star property, observed that higher shower flow rates are a common feature of luxury resorts, and some organizations avoid reduction efforts because they can result in customer complaints.

Reducing energy consumption associated with heating water for guestrooms is another important best practice that ultimately saves water (Styles et al., 2015). Providing hot water also adds significantly to operating costs by increasing energy use (European Commission, 2014). Here the hotel managers exceeded best practices by installing solar hot water systems, eliminating the environmental and financial impact of hot water generation across their properties.

Housekeeping. Minimizing the amount of water used to clean rooms and common areas is another area of best practice identified by Styles et al. (2015). While Styles et al. (2015) mainly focused on limiting the number of toilet flushes and the time that taps run during room cleaning, the managers at the hotels in this study highlighted additional creative water-saving strategies. Participant 1, the general manager of a 3-star property, described how housekeepers cleaned with cloths (no mops) and cleaned an entire floor of rooms with just 5 liters of water. 
Participant 8, the housekeeping director at the 5-star hotel, described a special mop that requires only 2 liters of water to clean a large area. Participants at both these hotels reported using water-efficient equipment to clean floors in common areas.

Laundry. Linen and towel reuse is nearly ubiquitous across the hotel sector as a water-and energy-saving strategy. Styles et al. (2015) advocated minimizing laundry loads by reducing the volume of bedclothes and towels taken for washing by $30 \%$. Participant 9 reported initiating an opt-out linen and towel reuse program across the three Canarian properties in 2016 , reducing the volume of laundry by $50 \%$ by changing sheets and towels two times per week unless otherwise directed by the guest; this policy exceeded the best practice benchmark. Styles et al. (2015) also identified outsourcing to large offsite laundries that can save water through economies of scale. Analysis of hotel documents showed that the participants followed this strategy.

Kitchens. Best practices in kitchen water supply management involve measuring and metering water use, maintaining water-efficient fittings and cleaning equipment, and controlling water consumption in cooking and cleaning (Styles et al., 2015). Participants 3 and 7, a food and beverage manager and a chef, respectively, mentioned several water-saving strategies related to pedal-operated taps and waterless cooking and thawing techniques. In addition, Participant 7 said kitchen staff saved water by boiling or cooking all food in ovens (rather than boiling or simmering on a stovetop) and cleaned vegetables in an 8-liter bucket of water with bleach. Participants pointed to the use of water-efficient dishwashers and other water-saving dishwashing techniques such as ensuring full loads. Managers said that they pay the same level of attention to preventing and fixing leaks in the kitchen as in the rest of the hotel.

Pools. Styles et al. (2015) did not identify a quantitative benchmark for pool water management but mentioned employing natural filtration systems, optimizing backwashing, and minimizing evaporation and leakage as preferred strategies. According to hotel documents, two of the hotels had natural filtration systems, while one (a 5-star property) had a less efficient sand filtration system with plans to upgrade in the future. Documents indicated that all three hotels minimize chemical use through salt ionizing systems that reduced the amount of chlorine used for disinfection.

Cooling and irrigation. Avoiding the use of drinking water in building systems and irrigation of green spaces is considered best practice (Styles et al., 2015). It was not possible to confirm whether the three hotels in this study substituted greywater for potable water in building systems. However, participants from the two more upscale hotels reported using their onsite water treatment plant to recycle water from baths, showers, and hand basins for irrigating elaborate gardens and green spaces. Participant 2, the facilities manager at the 3-star property, said there was no capacity to recycle greywater but felt it was less important because the hotel had a very small garden. Document analysis showed that all three hotels conserved water by using drip and micro-spray irrigation to maintain gardens and grounds.

Awareness (staff and guests). The literature indicates that managers' knowledge and capabilities can influence the success or failure of environmental and social responsibility initiatives in firms (Del Mar Alonso-Almeida et al., 2017; Peiro-Signes \& Segarra-Oña, 2017). Participants confirmed that they purposefully applied knowledge and dynamic capabilities to promote water efficiency and conservation goals in these hotels. Bromiley and Rau (2014) noted that according to RBV theory, the dissemination of knowledge and promotion of new competencies through the organizational culture was a resource in and of itself. The orientation of the managers helped diffuse knowledge through organizational culture (Peiro-Signes \& Segarra-Oña, 2017). Participants in this study reported actively building a culture of water efficiency and conservation in the hotels by disseminating knowledge and promoting new competencies. Water supply management (along with energy conservation) was part of annual objectives for general managers. Participant 5 said, "The first knowledge to share, develop, and defend is the social-environmental concept of water as a scarce resource (...) and then develop appropriate environmental 
practices in the efficient and rational use of water." The challenge, he added, was continuing to ensure that everyone is aware, motivated and committed to water efficiency and conservation.

"The most important thing is staff engagement," said Participants 7, a chef, who described holding daily meetings with kitchen staff to review consumption, identify problems, and develop strategies to eliminate waste. New employees receive special training in water efficiency and other environmental issues. The corporate office reinforces this message at annual environmental workshops and provides ongoing strategic support.

Environmental certifications. The certifying agency, TraveLife, is another source of knowledge the hotel managers exploit. Participant 5 said that as an independent resource, TraveLife helped "professionalize" the hotels' environmental programs, detect anomalies, and implement additional measures "integral to the water management process." The managers also extended the culture of water conservation to the guests. Participant 1 said that guests are generally aware that they are visiting a water-stressed area and are willing to accommodate water conservation efforts.

Nevertheless, participants reinforced the water conservation mindset in guests by providing information about water-saving strategies in rooms and other areas of the property. The local government also runs awareness campaigns on water conservation, primarily aimed at the local population, which serve to remind tourists not to waste water as well. Managers in this study created a culture of water conservation through staff engagement, regular training, and frequent communication with employees and guests. These practices made water conservation part of every employee's job, diffusing water saving goals through all levels of the organization.

\subsection{Theme 4. Sustain supply through Corporate Water Stewardship (CWS)}

Water stewardship involves voluntary participation in water governance by corporate water-users (Sojamo, 2015). Data analysis showed evidence that the hotel managers made efforts to sustain the resource base to ensure their supply while considering the community's well-being.

Hotel water stewardship. CWS is an emerging business practice for water-intensive businesses (Sojamo, 2015). In CWS, businesses cooperate in sustaining the resource base for their own benefit while also considering community well-being. Participant 5 recognized how dependent the hotel business was on the continuing health of the islands' water supply and expressed his commitment to stewardship as "the contribution that, as a company, you make to the sustainability of the geographical destination that welcomes and gives shelter to your economic activity." In addition to economic (instrumental) motivation, CWS also is linked to ethical (social responsibility) motivations (Martinez, 2015). Participants consistently expressed concern about water availability beyond the walls of their own business. Participant 5 stressed the importance of "making more water available to the society in which you operate by consuming just what you need, without wasting one cubic meter more." According to hotel documents, managers certify that their hotels' usage does not impact the availability of local supply in accordance with local regulations.

CWS involves collaboration with government and competing water users to allocate water resources equitably. Participants characterized their hotels' participation in local water governance in terms of respecting the current norms, applying policies and measures of environmental sustainability and efficient resources use, and collaborating in the implementation of additional measures that contribute to improving water management. Another way these hotel managers engaged in water governance was through pollution prevention. Managers paid for disposal and treatment of wastewater through an onsite treatment plant and maintained an emergency pollution prevention plan. Managers also monitored wastewater for pollutants, particularly fecal bacteria. Over the years, unauthorized discharge of raw sewage into the sea caused serious contamination and microalgae blooms in coastal waters, closing beaches and harming the image of the islands as a sun and beach tourism destination (Anscombe, 2018). 
Climate change. Participants 1 and 5 noted the impact of climate change on the Canary Islands, describing longer summers, heavier rain during the short winters, and more extreme storms. Summer sand storms emanating from the Sahara Desert also occur with greater frequency due to increasing desertification in nearby Africa. Participant 1 predicted that this process would increase water demand for residents, tourists, and farmers. When asked if climate-change induced water scarcity could potentially provoke competition between the sectors for water resources, Participant 5 replied that rather than competing, the hotels and agricultural sector would be inclined to collaborate "since hotels prefer to have a continuous supply of local food products rather than import from outside." To meet this demand, Participant 5 continued, "an increasing number of desalination facilities will be required, causing our coasts to be flooded with these types of industrial facilities, which also cause environmental problems of all kinds."

\section{Conclusions and recommendations}

Business leaders face substantial risks from growing water scarcity (World Economic Forum, 2016). As highquality water supplies decline, production costs and prices are likely to rise, impacting hotel performance and profitability (Barberán et al., 2013). Interruptions in water supply could threaten service delivery and diminish guest satisfaction. Competition for water with other users could deplete the resource base and endanger community support (Styles et al., 2015). The problem is that some hotel managers lack strategies for maintaining adequate water supplies.

By studying managers operating hotels in a historically water-stressed tourism region, the study was able to highlight how owners, operators, and managers in other hotels might address water scarcity. The findings suggest that hotel managers should first and foremost value water as an essential business input. In general, the hotel management literature seems to take water supply for granted while devoting the preponderance of the attention to energy. But industry professionals may be overlooking an important source of competitive advantage, which could become more important to business performance. As water supplies decrease and costs rise in many regions of the world, hotel operators may become more motivated to emulate the managers involved in this study.

The experience of the study participants suggests that hotel managers could do more to mitigate the risks of natural resource scarcity by investing in innovative technologies. Bell et al. (2013) remarked that economists typically expect substitution and innovation to offset resource scarcity-based risks. In this study, desalination and water recovery and recycling were the most prominent innovative substitution strategies. Although desalination technology is highly advanced in the Canary Islands, it is not infallible and cannot easily be applied at the property level, while resource recovery and recycling can. Based on these findings, hotel managers operating in regions with limited or uncertain water supplies should consider more aggressive investment in water recovery and recycling technology and methods at the property level. They might also advocate with local government to enhance public investment in these technologies.

Water efficiency and water conservation practices are common in the hotel industry, but a review of the academic and professional literature indicated that no single set of practices would guarantee optimal water supply in every hotel. Differences in size, age, type, occupancy, amenities, location, climate, and many other factors affect overall water usage as well as water efficiency. The managers in this study implemented comprehensive environmental programs with significant efforts devoted to water efficiency and conservation, but these programs did not include all the best practices identified by Styles et al. (2015). These limitations reflect a continuing challenge for hotel managers concerning water scarcity: to conserve water while providing the luxury experience expected by guests in upscale resort settings. 
Hotel managers also favor practices that are low-cost, practical, and cost-saving over those that require greater investment and take time to pay back (Becken \& Dolcinar, 2016). Retrofitting fixtures and instituting water recovery systems take time, planning, and resources. The managers in this study relied on the TraveLife ecocertification standard to help develop their programs. However, as Styles et al. (2015) pointed out, certifications often fail to produce quantitative water efficiency. Therefore, these findings also imply that to achieve optimal water efficiency, hotel managers should look beyond certifications to optimize water efficiency based on their location and hotel type.

Finally, the managers in this study practiced CWS in recognition of their dependence on the health of the local environment and the goodwill of the local community. By adopting policies and practices that helped sustain the resource base, the managers not only helped themselves but also helped support local agriculture and a thriving local population that can participate in the economy. By looking beyond the walls of their own business, other hotel managers can reap the rewards of water stewardship.

The results of this study may lead to a better understanding of water challenges in hotels and broader adoption of benchmarks of excellence by industry leaders, multinational hotel group executives, and hotel managers at all levels. Hotel environmental management is a patchwork of different standards and approaches to water supply management, all of them aiming to save resources, reduce costs, and maintain the supply of high-quality water while preserving water availability for the surrounding community. Unfortunately, not all approaches produce measurable water efficiency at the property level (Styles et al., 2015). Hotel professionals, environmentalists, and academics should come together to establish an empirical benchmark of excellence for water efficiency for hotels at every service level to help standardize best practices and link them more directly with measurable outcomes.

\section{Bibliographic references}

Anscombe, J. (2018, January). Government unveils sewage and waste water census after 2017 figures show hundreds of unauthorized discharges into the sea. Retrieved from https://www.janetanscombe.com/news/sewage-wastewater-discharges-tenerife-coast.html

Barberán, R., Egea, P., Gracia-de-Rentería, P., \& Salvador, M. (2013). Evaluation of water saving measures in hotels: A Spanish case study. International Journal of Hospitality Management, 34, 181-191. doi:10.1016/j.ijhm.2013.02.005

Barney, J. (1991). Firm resources and sustained competitive advantage. Journal of Management, 17, 99-112. doi:10.1177/014920639101700108

Barney, J. (2001). Resource-based theories of competitive advantage: A ten-year retrospective on the resourcebased view. Journal of Management, 27(6), 643-650. doi:10.1177/0149206 30102700602

Baskarada, S. (2014). Qualitative case study guidelines. The Qualitative Report, 19(40), 1-18. Retrieved from http://nsuworks.nova.edu/tqr/vol19/iss40/3

Becken, S. (2014). Water equity: Contrasting tourism water use with that of the local community. Water Resources and Industry, 7, 9-22. doi:10.1016/j.wri.2014. 09.002

Becken, S., \& Dolnicar, S. (2016). Uptake of resource efficiency measures among European small- and mediumsized accommodation and food service providers. Journal of Hospitality and Tourism Management, 26, 4549. doi:10.1016/j.jhtm.2015.11.001 
Becken, S., Garafano, N., McLennan, C. L., Moore, S., Rajan, R., \& Watt, M. (2014). Second white paper on tourism and water: Providing the business case. Queensland, Australia: Griffith Institute for Tourism Research. Retrieved from https://www.griffith.edu.au/

Bell, J. E., Mollenkopf, D. A., \& Stolze, H. J. (2013). Natural resource scarcity and the closed-loop supply chain: A resource-advantage view. International Journal of Physical Distribution \& Logistics Management, 43(5/6), 351-379. doi:10.1108/ IJPDLM-03-2012-0092

Božič, V., \& Cvelbar, L. K. (2016). Resources and capabilities driving performance in the hotel industry. Tourism and Hospitality Management, 22(2), 225-246. doi:10.20867/thm.22.2.8

Bromiley, P., \& Rau, D. (2014). Towards a practice-based view of strategy. Strategic Management Journal, 35(8), 1,249-1,256. doi:10.1002/smj.2238

Bruns-Smith, A., Choy, V., Chong, H., \& Verma, R. (2015). Environmental sustainability in the hospitality industry: Best practices, guest participation, and customer satisfaction. Cornell Hospitality Reports, 15(3), 6-16. Retrieved from www.chr.cornell.edu

CBRE Hotels. (2018, May-June). Hotel horizons. Retrieved from https://pip. cbrehotels.com/ publications-dataproducts/hotel-horizons

Custodio, E., del Carmen Cabrera, M., Poncela, R., Cruz-Fuentes, T., Naranjo, G., \& Puga de Miguel, L. (2015). Comments on uncertainty in groundwater governance in the volcanic Canary Islands, Spain. Water, 7, 2,952-2,970. doi:10.3390/ w7062952

Custodio, E., del Carmen Cabrera, M., Poncela, R., Puga de Miguel, L. O., Skupien, E., \& del Villar, A. (2016). Groundwater intensive exploitation and mining in Gran Canaria and Tenerife, Canary Islands, Spain: Hydrogeological, environmental, economic and social aspects. Science of the Total Environment, 557, 425437. doi:10.1016/j.scitotenv.2016.03.038

Da Rosa, F. S., \& Silva, L. C. (2017). Environmental sustainability in hotels: Theoretical and methodological contribution. Revista Brasileira de Pesquisa em Turismo, 11, 39-60. doi:10.7784/rbtur.v11i1.1161

Dasgupta, M. (2015). Exploring the relevance of case study research. Vision, 19, 147-160. doi:10.1177/0972262915575661

De Massis, A., \& Kotlar, J. (2014). The case study method in family business research: Guidelines for qualitative scholarship. Journal of Family Business Strategy, 5, 15-29. doi:10.1016/j.jfbs.2014.01.007

Del Mar Alonso-Almeida, M., Buil-Fabregà, M., Bagur-Femenías, L., \& Aznar-Alarcón, J. P. (2017). Shedding light on sustainable development and stakeholder engagement: The role of individual dynamic capabilities. Sustainable Development, 25, 1,099-1,719. doi:10. 1002/sd.1682

DeSouza, M. (2016). Coping with water scarcity in agriculture: A global framework for action in a changing climate (Job No. 15604E). Retrieved from http://www. fao.org/documents/ card/en/c/8dd680fd-70d34725-8d9f-30f9a02455a0

Deya-Tortella, B., Garcia, C., Nilsson, W., \& Tiraddo, D. (2017). The effect of the water tariff structures on the water consumption in Mallorcan hotels. Water Resources Research, 52(8), 6,386-6,403. doi:10.1002/2016WR018621 
Diefenbach, T. (2009). Are case studies more than sophisticated storytelling? Methodological problems of qualitative empirical research mainly based on semi-structured interviews. Quality \& Quantity, 43(6), 875894. doi:10.1007/s11135-008-9164-0

Enriquez de la O, J. F. (2015). Resource-based view and dynamic capabilities: Achieving competitive advantage through internal resources and competencies. Vezetéstudomány/Budapest Management Review, 46(11), 50-61. Retrieved from http://corvinus-mba.hu/school/research-publications

European Commission, Lifelong Learning Program. (2014). Green games in tourism \& hospitality: State of the art report. Retrieved from http://greengamesproject.com/ learning-resources/state-of-the-art-report

Fusch, P. I., \& Ness, L. (2015). Are we there yet? Data saturation in qualitative research: The Qualitative Report, 20, 1,408-1,416. Retrieved from http://tqr.nova.edu

García-Rodríguez, J. L., García-Rodríguez, F. J., \& Castilla-Gutiérrez, C. (2016). Human heritage and sustainable development on arid islands: The case of the Eastern Canary Islands. Island Studies Journal, 11(1), 113-130. Retrieved from https:// www.island scholar.ca

Gössling, S. (2015). New performance indicators for water management in tourism. Tourism Management, 46, 233-244. doi:10.1016/j.tourman.2014.06.018

Gössling, S., Peeters, P., Hall, C. M., Ceron, J. P., Dubois, G., \& Scott, D. (2012). Tourism and water use: Supply, demand, and security: An international review. Tourism Management, 33(1), 1-15. doi:10.1016/j.tourman.2011.03.015

Guarino, A. S. (2017). The economic implications of global water scarcity. Research in Economics and Management, 2(1), 51- 63. doi:10.22158/rem.v2n1p51

Hancock, D. R., \& Algozzine, B. (2017). Doing case study research: A practical guide for beginning researchers. ( $3^{\text {rd }}$ ed.) New York, NY: Teachers College Press.

Kasim, A., Gursoy, D., Okumus, F., \& Wong, A. (2014). The importance of water management in hotels: A framework for sustainability through innovation. Journal of Sustainable Tourism, 22(7), 1,090-1,107. doi:10.1080/09669582.2013. 87344

Malterud, K., Siersma1, V. D., \& Guassora, A. D. (2016). Sample size in qualitative interview studies: Guided by information power. Qualitative Health Research, 26, 1,753-1,760. doi:10.1177/1049732315617444

Martinez, F. (2015). A three-dimensional conceptual framework of corporate water responsibility. Organization \& Environment, 28(2), 137-159. doi:10.1177/ 1086026614545632

Marques, R. C., Pinto, F. S., \& Miranda, J. (2016). Redrafting water governance: Guiding the way to improve the status quo. Utilities Policy, 43, 1-3. doi:10.1016/j.jup. 2016.11.002

Molina-Azorín, J. F., Tarí, J. J., Pereira-Moliner, J., López-Gamero, M. D., \& Pertusa-Ortega, E. M. (2015). The effects of quality and environmental management on competitive advantage: A mixed methods study in the hotel industry. Tourism Management, 50, 41-54. doi:10.1016/j.tourman.2015.01.008

Peiro-Signes, A., \& Segarra-Oña, M. (2017). Looking for determinants of the environmental concern in the hospitality industry. In V. Katsoni, A. Upadhya, \& A. Stratigea (Eds.), Tourism, culture, and heritage in a smart economy (pp. 173-181). Cham, Switzerland: Springer International AG. 
Robinson, O. C. (2013). Sampling in interview-based qualitative research: A theoretical and practical guide. Qualitative Research in Psychology, 11, 25-41. doi:10. 1080/14780887. 2013.801543

Salazar, L. A. L. (2017). The resource-based view and the concept of value: The role of emergence in value creation. Mercados y Negocios, 1(35), 27-46. Retrieved from http://www.revistascientificas.udg.mx

Sojamo, S. (2015). Unlocking the "prisoner's dilemma" of corporate water stewardship in South Africa: Exploring corporate power and legitimacy of engagement in water management and governance. Sustainability, 7(6), 6,893-6,918. doi:10.3390/ su7066893

Stake, R. E. (1995). The art of case study research. Thousand Oaks, CA: Sage.

Styles, D., Schoenberger, H., \& Galvez-Martos, J. L. (2015). Water management in the European hospitality sector: Best practice, performance benchmarks, and improvement potential. Tourism Management, 46, 187-202. doi:10.1016/j. tourman.2014.07.005

Tan, S. H., Habibullah, M. S., Tan, S. K., \& Choon, S. W. (2017). The impact of the dimensions of environmental performance on firm performance in the travel and tourism industry. Journal of Environmental Management, 203, 603-611. doi:10. 1016/j.jenvman.2017. 02.029

World Economic Forum. (2016). Global risks report 2016. Retrieved from http://reports. weforum.org/globalrisks-2016/

Yin, R. K. (2017). Case study research: Designs and methods (6th ed.). Thousand Oaks, CA: Sage.

Zhang, J. J., Joglekar, N., Heineke, J., \& Verma, R. (2014). Eco-efficiency of service co-production: Connecting eco-certifications and resource efficiency in U.S. hotels. Cornell Hospitality Quarterly, 55, 252-264. doi:10.1177/19389655Insert

Esta obra está bajo una Licencia Creative Commons Attribución-NoCommercial 4.0 International

(cc) BY-NC 